\title{
Magnetic Properties of Sm-Fe-N/Co-B Composite Magnets Prepared by Chemical Reduction
}

\author{
Tetsuji Saito \\ Department of Mechanical Science and Engineering, Chiba Institute of Technology, 2-17-1 Tsudanuma, Narashino, \\ Chiba 275-0016, Japan \\ Correspondence should be addressed to Tetsuji Saito; tetsuji.saito@it-chiba.ac.jp
}

Received 9 March 2017; Revised 6 April 2017; Accepted 11 April 2017; Published 24 April 2017

Academic Editor: Jörg Fink

Copyright (C) 2017 Tetsuji Saito. This is an open access article distributed under the Creative Commons Attribution License, which permits unrestricted use, distribution, and reproduction in any medium, provided the original work is properly cited.

An attempt was made to produce $\mathrm{Sm}-\mathrm{Fe}-\mathrm{N} / \mathrm{Co}-\mathrm{B}$ composite magnets by chemical reduction. It was found that a composite powder consisting of Sm-Fe-N particles coated with fine Co-B particles could be obtained by chemical reduction. The Sm-Fe-N/Co-B composite powder acted as a single hard magnetic phase and showed a smooth hysteresis loop. The composite powder exhibited a higher remanence of $93.1 \mathrm{Am}^{2} / \mathrm{kg}$ and a higher coercivity of $0.45 \mathrm{MA} / \mathrm{m}$ than a mixture of the Sm-Fe-N powder and Co-B powder prepared by a similar procedure but using a higher concentration of aqueous solution for the chemical reduction.

\section{Introduction}

With the advent of high-energy-product Nd-Fe-B permanent magnets, research and development of new permanent magnetic materials have mainly been concentrated on rare-earthcontaining alloys $[1,2]$. As a consequence of intensive studies of Nd-Fe-B permanent magnets, their maximum energy product has been improved to the point where it has reached the practical limits of these magnets [3-5]. Researchers in this field are thus placing expectations on the development of new types of permanent magnets. One approach is to investigate the new permanent magnetic materials. Among the candidates for such materials is $\mathrm{Sm}_{2} \mathrm{Fe}_{17} \mathrm{~N}_{3}$ compound [6]. Although $\mathrm{Sm}_{2} \mathrm{Fe}_{17} \mathrm{~N}_{3}$ compound exhibits a high saturation magnetization and a large coercivity comparable to those of Nd-Fe-B magnets, it is obtained in powder form. Hence, unlike the case of the Nd-Fe-B sintered magnets, conventional sintering techniques cannot be applied to the production of Sm-Fe-N bulk magnets [6]. Another candidate is the $\mathrm{Sm}_{5} \mathrm{Fe}_{17}$ phase [7]. The $\mathrm{Sm}_{5} \mathrm{Fe}_{17}$ phase is a new ferromagnetic phase in the binary $\mathrm{Sm}$-Fe system $[8,9]$. The coercivity of the $\mathrm{Sm}_{5} \mathrm{Fe}_{17}$ phase is much larger than that of $\mathrm{Nd}-\mathrm{Fe}-\mathrm{B}$ magnets, but its remanence is much lower, at around $40 \mathrm{Am}^{2} / \mathrm{kg}[4,5]$. The outlook for the discovering of new magnetic phases with a maximum energy product exceeding that of Nd-Fe-B magnets is therefore not promising.
Another approach is to improve the magnetic properties of nanocomposite magnets, one of the new types of permanent magnets [10]. Nanocomposite magnets are composed of a mixture of nanosize soft magnetic and hard magnetic phases. It is known that the existence of the soft magnetic phase in a permanent magnet weakens the remanence and maximum energy products. Due to exchange coupling of the nanosize soft magnetic and hard magnetic phases, however, nanocomposite magnets exhibit a higher remanence than the conventional magnets. Anisotropic nanocomposite magnets are expected to show giant maximum energy products as high as $1 \mathrm{MJ} / \mathrm{m}^{3}$ when the soft magnetic and hard magnetic phases are arranged in the optimal manner [11]. Nanocomposite magnets are currently produced by annealing of melt-spun ribbons [12-15]. Figure 1(a) shows a schematic representation of nanocomposite powder prepared from nanocomposite melt-spun ribbon. The nanocomposite powder consists of a number of soft and hard magnetic phases, with the hard magnetic phase randomly oriented. Thus, nanocomposite powder prepared from nanocomposite melt-spun ribbon is magnetically isotropic. Nanocomposite magnets produced by the consolidation of such nanocomposite powders are also magnetically isotropic and show a much lower remanence and maximum energy product than anisotropic nanocomposite magnets [16-19]. From this standpoint, magnetically isotropic melt-spun ribbons or mechanically alloyed powders 


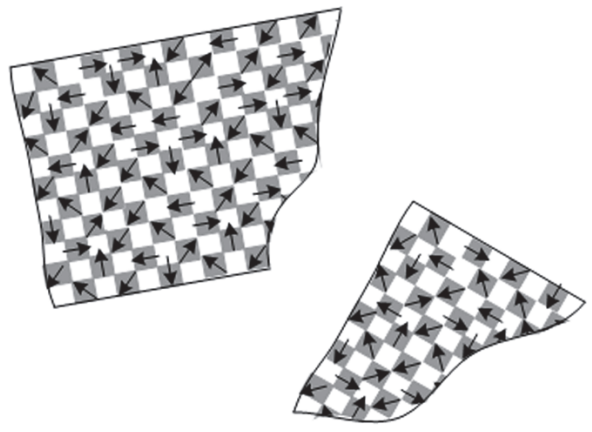

(a)
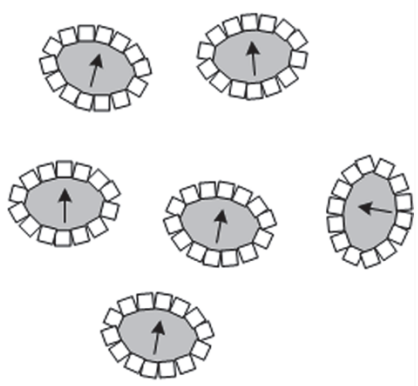

(b)

FIGURE 1: Schematic diagrams of (a) nanocomposite powder prepared by crushing melt-spun ribbon and (b) proposed nanocomposite powder. The white and gray regions indicate the soft and hard magnetic phases, respectively. The arrows indicate the magnetic moment of the hard magnetic phase.

are not suitable for the production of anisotropic nanocomposite magnets with a high energy product. In order to produce anisotropic nanocomposite magnets, it is essential to produce a different type of composite powder, as shown in Figure 1(b), where particles of hard magnetic powder are coated with or surrounded by particles of soft magnetic powder.

It has been reported that soft magnetic powder can be produced by chemical reduction $[20,21]$. Unlike the meltspinning or mechanical alloying techniques, this method can produce fine powders directly from a metallic solution. Thus, composite powder may be obtained by chemical reduction if the fine hard magnetic powder is stable in the metallic solution. Since Sm-Fe-N magnets can be produced in powder form, Sm-Fe-N powder was selected as the hard magnetic powder in this study. The purpose of this study was to investigate the possibility of producing $\mathrm{Sm}-\mathrm{Fe}-\mathrm{N} / \mathrm{Co}-\mathrm{B}$ composite powder by chemical reduction. Co-B powder was chosen as the soft magnetic powder because the Co-B powder was easily produced by the chemical reduction. The detailed processing conditions for the production of Sm-Fe-N/Co-B composite powder are described here, and the magnetic properties of the powder are discussed.

\section{Experiment}

Commercially available $\mathrm{Sm}_{2} \mathrm{Fe}_{17} \mathrm{~N}_{3}$ powder produced by Sumitomo Metal Mining Co., Ltd., was used in the experiment. The average particle size of the original Sm-Fe-N powder was about $3 \mu \mathrm{m}$. An aqueous solution of sodium borohydride $\left(\mathrm{NaBH}_{4}\right)$ was added to the aqueous solution of cobalt sulfate heptahydrate $\left(\mathrm{CoSo}_{4} \cdot 7 \mathrm{H}_{2} \mathrm{O}\right)$ containing $\mathrm{Sm}_{2} \mathrm{Fe}_{17} \mathrm{~N}_{3}$ powder. The $\mathrm{pH}$ of the solution was constantly maintained at 5.5 by the addition of sodium hydroxide $(\mathrm{NaOH})$ or hydrochloric acid $(\mathrm{HCl})$ during the chemical reduction. The black precipitate was collected on a filter, washed quickly with a large amount of ethanol, and stored in an ethanol filled vessel. The morphology of the powder was investigated under a scanning electron microscope (SEM) and a transmission electron microscope (TEM). After the powder had been mixed with epoxy, its hysteresis loop was measured by a vibrating sample magnetometer (VSM) with a maximum applied field of $2 \mathrm{MA} / \mathrm{m}$. The VSM was calibrated with a pure nickel sphere.

\section{Results and Discussion}

In the production of composite materials by chemical reduction, it is essential to examine the stability of the hard magnetic phase, in this case, $\mathrm{Sm}-\mathrm{Fe}-\mathrm{N}$ powder in the acid or alkali solution used for the chemical reduction. A preliminary study revealed that the $\mathrm{Sm}-\mathrm{Fe}-\mathrm{N}$ powder was not stable in the alkali solution used for the production of Co-P powder but was stable in the acid solution used for the production of Co-B powder. Thus, the production of Sm-Fe-N/Co-B composite powder by chemical reduction was pursued in this experiment. The main problems to be overcome were the tendency of fine powder to agglomerate and finding a way to obtain a powder consisting of $\mathrm{Sm}-\mathrm{Fe}-\mathrm{N}$ particles coated with Co-B particles. In order to produce such a powder, the amount of Sm-Fe-N powder was fixed and the concentration of the aqueous solution of cobalt sulfate heptahydrate was changed from $0.025 \mathrm{~mol} / \mathrm{l}$ to $0.100 \mathrm{~mol} / 1$. Figure 2 shows SEM micrographs of the Sm-Fe-N/Co-B composite powders produced by chemical reduction. In Figure 2(a), showing the powder prepared using an aqueous solution of $0.1 \mathrm{~mol} / \mathrm{l}$ cobalt sulfate heptahydrate, relatively large angular Sm-Fe$\mathrm{N}$ particles, with an average size of about $3 \mu \mathrm{m}$, are clearly observed, surrounded by fine agglomerated particles of Co-B. The average particle size of the Co-B particles was determined to be about $20 \mathrm{~nm}$ by TEM studies. The existence of the SmFe-N particles did not disturb the formation of the Co-B particles by the chemical reduction, and the resultant powder consisted of a mixture of the Sm-Fe-N and Co-B particles. On the other hand, as shown in Figure 2(b), no individual Sm-Fe$\mathrm{N}$ particles are seen in the powder prepared using an aqueous solution of $0.025 \mathrm{~mol} / \mathrm{l}$ cobalt sulfate heptahydrate. Each Sm$\mathrm{Fe}-\mathrm{N}$ particle is coated with fine Co-B particles. Hence, the use of an aqueous solution of cobalt sulfate heptahydrate at a lower concentration resulted in the Sm-Fe-N particles being coated with fine Co-B particles formed during the chemical reduction without the occurrence of agglomeration. 


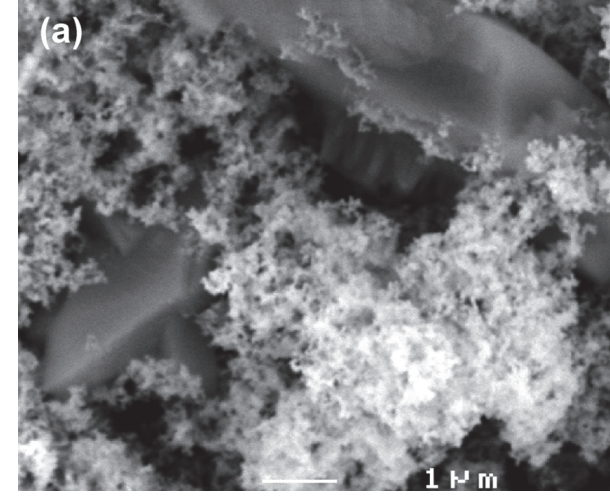

(a)

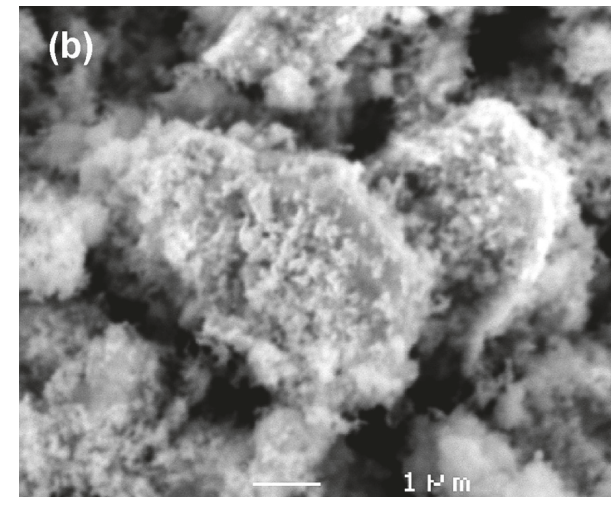

(b)

FIGURE 2: SEM micrograph of Sm-Fe-N/Co-B composite powders prepared by chemical reduction using an aqueous solution of (a) $0.1 \mathrm{~mol} / \mathrm{l}$ and (b) $0.025 \mathrm{~mol} / \mathrm{l}$ cobalt sulfate heptahydrate.

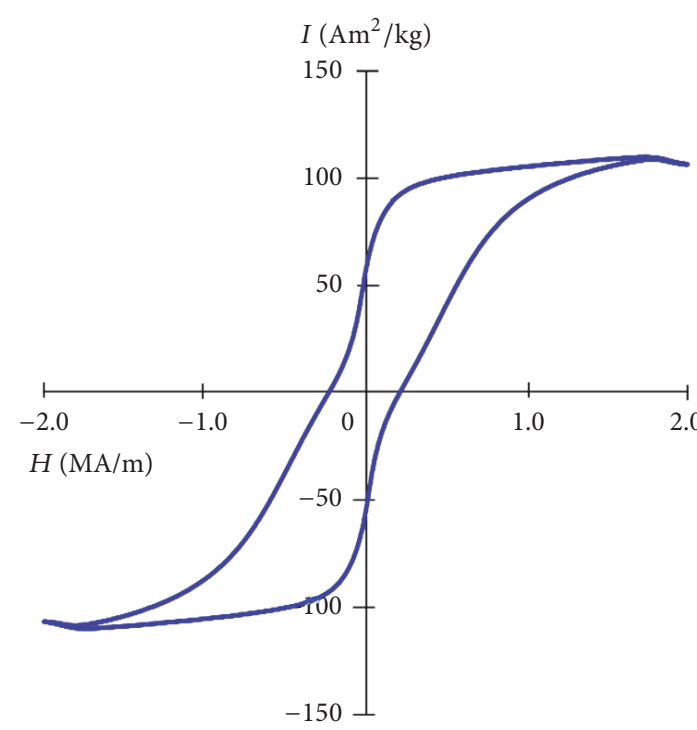

(a)

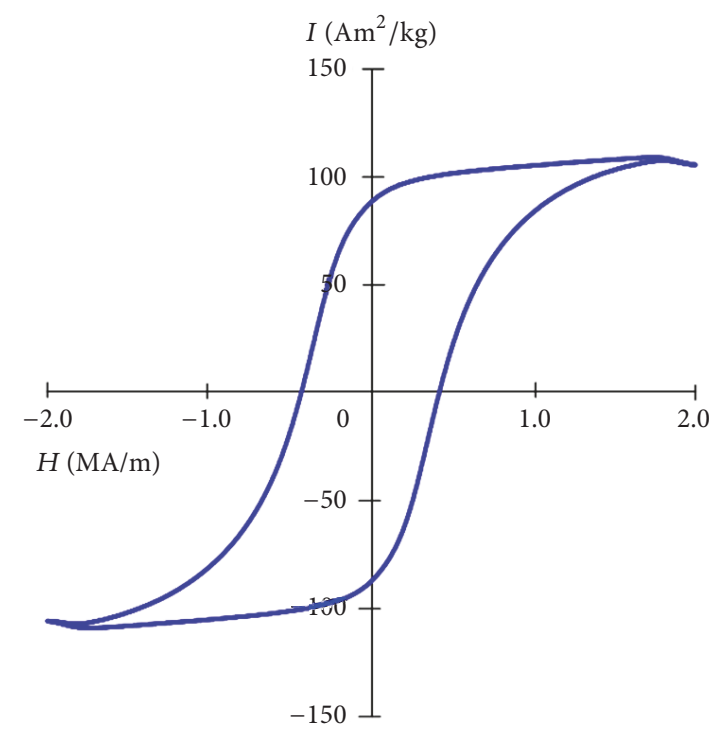

(b)

Figure 3: Hysteresis loops of Sm-Fe-N/Co-B composite powders prepared by chemical reduction using an aqueous solution of (a) 0.1 mol/l and (b) $0.025 \mathrm{~mol} / \mathrm{l}$ cobalt sulfate heptahydrate.

The magnetic properties of these Sm-Fe-N/Co-B composite powders prepared by chemical reduction were examined. The hysteresis loops are shown in Figure 3. The powder prepared using an aqueous solution of $0.1 \mathrm{~mol} / \mathrm{l}$ cobalt sulfate heptahydrate exhibits a remanence of $46.7 \mathrm{Am}^{2} / \mathrm{kg}$ with a coercivity of $0.22 \mathrm{MA} / \mathrm{m}$. However, a kink is seen in the hysteresis loop. This indicates that the specimen consists of two magnetic phases with different coercivity; in this case, the hard magnetic $\mathrm{Sm}-\mathrm{Fe}-\mathrm{N}$ phase with high coercivity and the soft magnetic Co-B phase with low coercivity. On the other hand, although the powder prepared using an aqueous solution of $0.025 \mathrm{~mol} / \mathrm{l}$ cobalt sulfate heptahydrate also consists of the hard magnetic Sm-Fe-N phase and the soft magnetic Co$\mathrm{B}$ phase, it has a smooth hysteresis loop. This indicates that the hard magnetic $\mathrm{Sm}-\mathrm{Fe}-\mathrm{N}$ particles covered with the soft magnetic Co-B particles act as one single hard magnetic powder, due to exchange coupling of the hard magnetic Sm-Fe-N phase and the soft magnetic Co-B phase. The resultant SmFe-N/Co-B composite powder exhibits a larger coercivity of $0.45 \mathrm{MA} / \mathrm{m}$ and a higher remanence of $93.1 \mathrm{Am}^{2} / \mathrm{kg}$ than the powder prepared using the aqueous solution of $0.1 \mathrm{~mol} / \mathrm{l} \mathrm{con-}$ centration. These magnetic properties of the Sm-Fe-N/Co$\mathrm{B}$ composite powder are very attractive for hard magnetic materials. Compositional modification and optimization of the processing conditions can be expected to lead to further improvement of the magnetic properties of $\mathrm{Sm}-\mathrm{Fe}-\mathrm{N} / \mathrm{Co}-\mathrm{B}$ composite powder prepared by chemical reduction.

\section{Conclusion}

Sm-Fe-N/Co-B composite powders were prepared by chemical reduction using aqueous solutions of cobalt sulfate heptahydrate. Isolated $\mathrm{Sm}-\mathrm{Fe}-\mathrm{N}$ particles were found when the powder was prepared by using an aqueous solution of 
$0.1 \mathrm{~mol} / \mathrm{l}$ cobalt sulfate heptahydrate. On the other hand, the $\mathrm{Sm}-\mathrm{Fe}-\mathrm{N}$ particles were coated with Co-B particles when the concentration of the aqueous solution was changed to $0.025 \mathrm{~mol} / \mathrm{l}$ cobalt sulfate heptahydrate. The resultant $\mathrm{Sm}-\mathrm{Fe}-$ $\mathrm{N} / \mathrm{Co}-\mathrm{B}$ composite powder acted as one single hard magnetic powder and exhibited a larger coercivity of $0.45 \mathrm{MA} / \mathrm{m}$ and a higher remanence of $93.1 \mathrm{Am}^{2} / \mathrm{kg}$ than the mixture of Sm-Fe$\mathrm{N}$ powder and Co-B powder.

\section{Conflicts of Interest}

The author declares no conflicts of interest.

\section{References}

[1] M. Sagawa, S. Fujimura, N. Togawa, H. Yamamoto, and Y. Matsuura, "New material for permanent magnets on a base of Nd and Fe," Journal of Applied Physics, vol. 55, no. 6, pp. 20832087, 1983.

[2] J. J. Croat, J. F. Herbst, R. W. Lee, and F. E. Pinkerton, "Pr-Fe and Nd-Fe-based materials: a new class of high-performance permanent magnets (invited)," Journal of Applied Physics, vol. 55, no. 6, pp. 2078-2082, 1984.

[3] K. de Kort, "Principle and practical limitations on the remanence and energy product of $\mathrm{Nd}_{2} \mathrm{Fe}_{14} \mathrm{~B}$ magnets," in Proceeding of the 14th International Workshop on Rare Earth Magnets and Applications, F. P. Missell, V. Villas-Boas, H. R. Rechenberg, and F. J. G. Landgraf, Eds., pp. 47-56, World Scientific Pub Co., 1996.

[4] W. Rodewald, B. Wall, M. Katter, K. Üstüner, and S. Steinmetz, "Extraordinary strong Nd-Fe-B magnets by a controlled microstructure," in Proceeding of the 17th International Workshop on Rare Earth Magnets and Applications, G. C. Hadjipanayis and M. J. Bonder, Eds., pp. 25-36, Rinton Press, 2002.

[5] T. Saito, M. Fujita, T. Kuji, K. Fukuoka, and Y. Syono, “The development of high performance Nd-Fe-Co-Ga-B die upset magnets," Journal of Applied Physics, vol. 83, no. 11, pp. 63906392, 1998.

[6] J. M. D. Coey and H. Sun, "Improved magnetic properties by treatment of iron-based rare earth intermetallic compounds in anmonia," Journal of Magnetism and Magnetic Materials, vol. 87, pp. L251-L254, 1990.

[7] T. Saito, "High coercivity in $\mathrm{Sm}_{5} \mathrm{Fe}_{17}$ melt-spun ribbon," Journal of Alloys and Compounds, vol. 440, pp. 315-318, 2007.

[8] H. H. Stadelmaier, G. Schneider, E.-T. Henig, and M. Ellner, "Magnetic Fel7R5 in the Fe-Nd and Fe(-Ti)-Sm systems, and other phases in Fe-Nd," Materials Letters, vol. 10, no. 7-8, pp. 303-309, 1991.

[9] A. C. Neiva and F. P. Missell, "The 5:17 phase in Sm-Nd-Fe," in Proceeding of the 8th International Symposium on Magnetic Anisotropy and Coercivity, C. A. F. Manwaring, Ed., pp. 315-324, University of Birmingham Press, 1994.

[10] R. Coehoorn, D. B. de Mooij, J. P. Duchateau, and K. H. J. Buschow, "Novel permanent magnetic materials made by rapid quenching," Journal de Physique, vol. 49, pp. C8-669-C8-670, 1988.

[11] R. Skomski and J. M. D. Coey, "Giant energy product in nanostructured two-phase magnets," Physical Review B, vol. 48, no. 21, pp. 15812-15816, 1993.

[12] I. Panagiotopoulos, L. Withanawasam, A. S. Murthy, G. C. Hadjipanayis, E. W. Singleton, and D. J. Sellmyer, "Magnetic hardening of melt-spun nanocomposite Nd2Fe14B/Fe magnets," Journal of Applied Physics, vol. 79, no. 8, pp. 4827-4829, 1996.

[13] M. Dahlgren, X. C. Kou, R. Grössinger et al., "Coercivity and spin reorientation transitions in $\mathrm{Nd}-\mathrm{Fe}-\mathrm{B}$ nanocomposites prepared by melt spinning," IEEE Transactions on Magnetics, vol. 33, no. 3, pp. 2366-2368, 1997.

[14] S. Hirosawa, Y. Shigemoto, T. Miyoshi, and H. Kanekiyo, "Direct formation of $\mathrm{Fe} 3 \mathrm{~B} / \mathrm{Nd} 2 \mathrm{Fe} 14 \mathrm{~B}$ nanocomposite permanent magnets in rapid solidification," Scripta Materialia, vol. 48, no. 7, pp. 839-844, 2003.

[15] W. C. Chang, D. Y. Chiou, S. H. Wu, B. M. Ma, and C. O. Bounds, "High performance $\alpha$-Fe $/ \mathrm{Nd}_{2} \mathrm{Fe}_{14} \mathrm{~B}$-type nanocomposites," Applied Physics Letters, vol. 72, pp. 121-123, 1998.

[16] J. Bauer, M. Seeger, A. Zern, and H. Kronmüller, "Nanocrystalline FeNdB permanent magnets with enhanced remanence," Journal of Applied Physics, vol. 80, no. 3, pp. 1667-1673, 1996.

[17] D. Goll, M. Seeger, and H. Kronmüller, "Magnetic and micro structural properties of nanocrystalline exchange coupled PrFeB permanent magnets," Journal of Magnetism and Magnetic Materials, vol. 185, no. 1, pp. 49-60, 1998.

[18] H. Ono, N. Waki, M. Shimada et al., "Isotropic bulk exchangespring magnets with $134 \mathrm{~kJ} / \mathrm{m} 3$ prepared by spark plasma sintering method," IEEE Transactions on Magnetics, vol. 37, no. 4, pp. 2552-2554, 2001.

[19] T. Saito, T. Takeuchi, and H. Kageyama, "Production of bulk amorphous and nanocomposite $\mathrm{Nd}_{4} \mathrm{Fe}_{77.5} \mathrm{~B}_{18.5}$ materials by spark plasma sintering method," IEEE Transactions on Magnetics, vol. 40, pp. 2880-2883, 2004.

[20] J. Saida, A. Inoue, and T. Masumoto, “The effect of reaction condition on composition and properties of ultrafine amorphous powders in ( $\mathrm{Fe}, \mathrm{Co}, \mathrm{Ni}$ )-b systems prepared by chemical reduction," Metallurgical Transactions A, vol. 22, no. 9, pp. 21252132, 1991.

[21] Z. Z. Yuan, J. M. Chen, Y. Lu, and X. D. Chen, "Preparation and magnetic properties of amorphous $\mathrm{Co}-\mathrm{Zr}-\mathrm{B}$ alloy nanopowders," Journal of Alloys and Compounds, vol. 450, pp. 245251, 2008. 

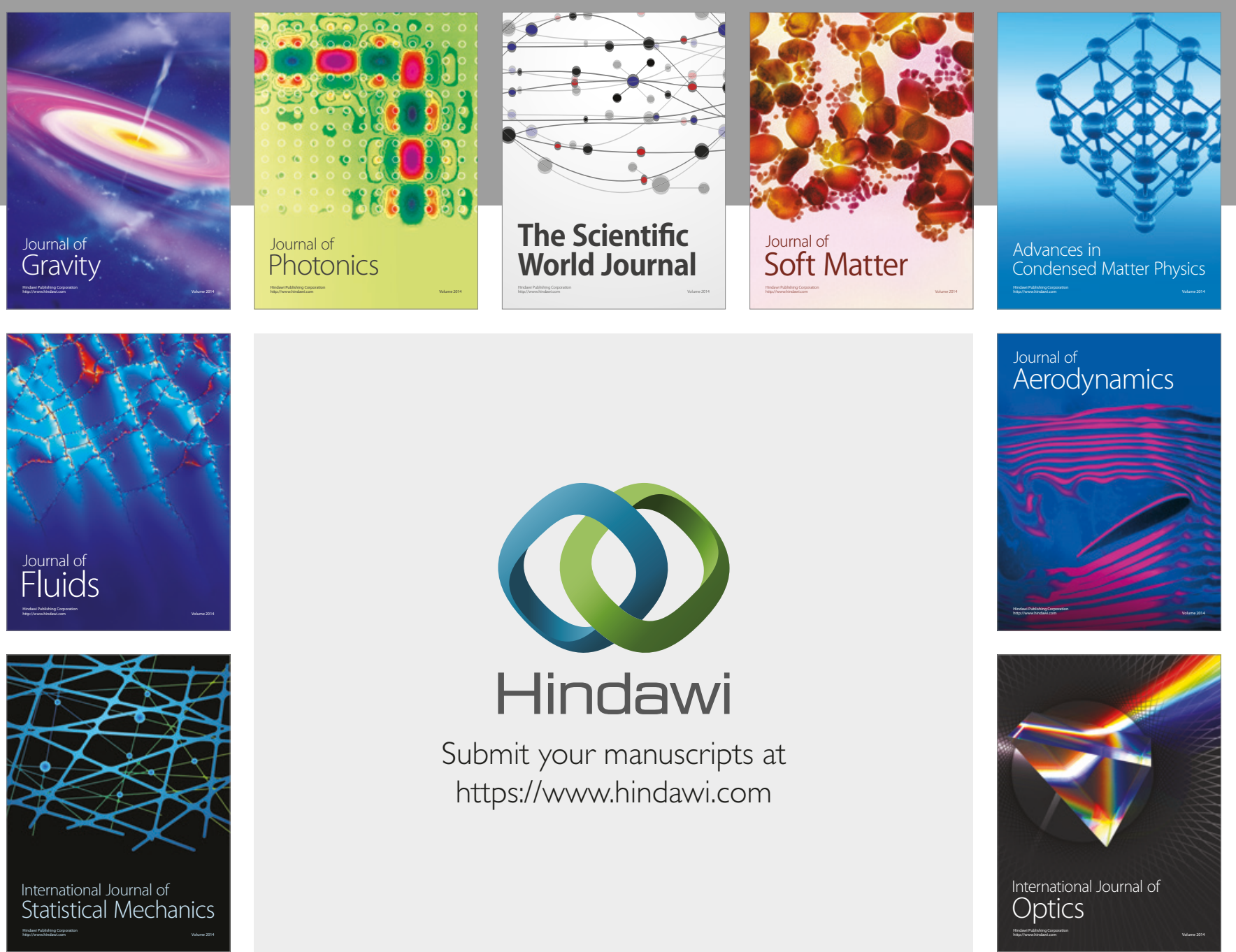

Submit your manuscripts at

https://www.hindawi.com
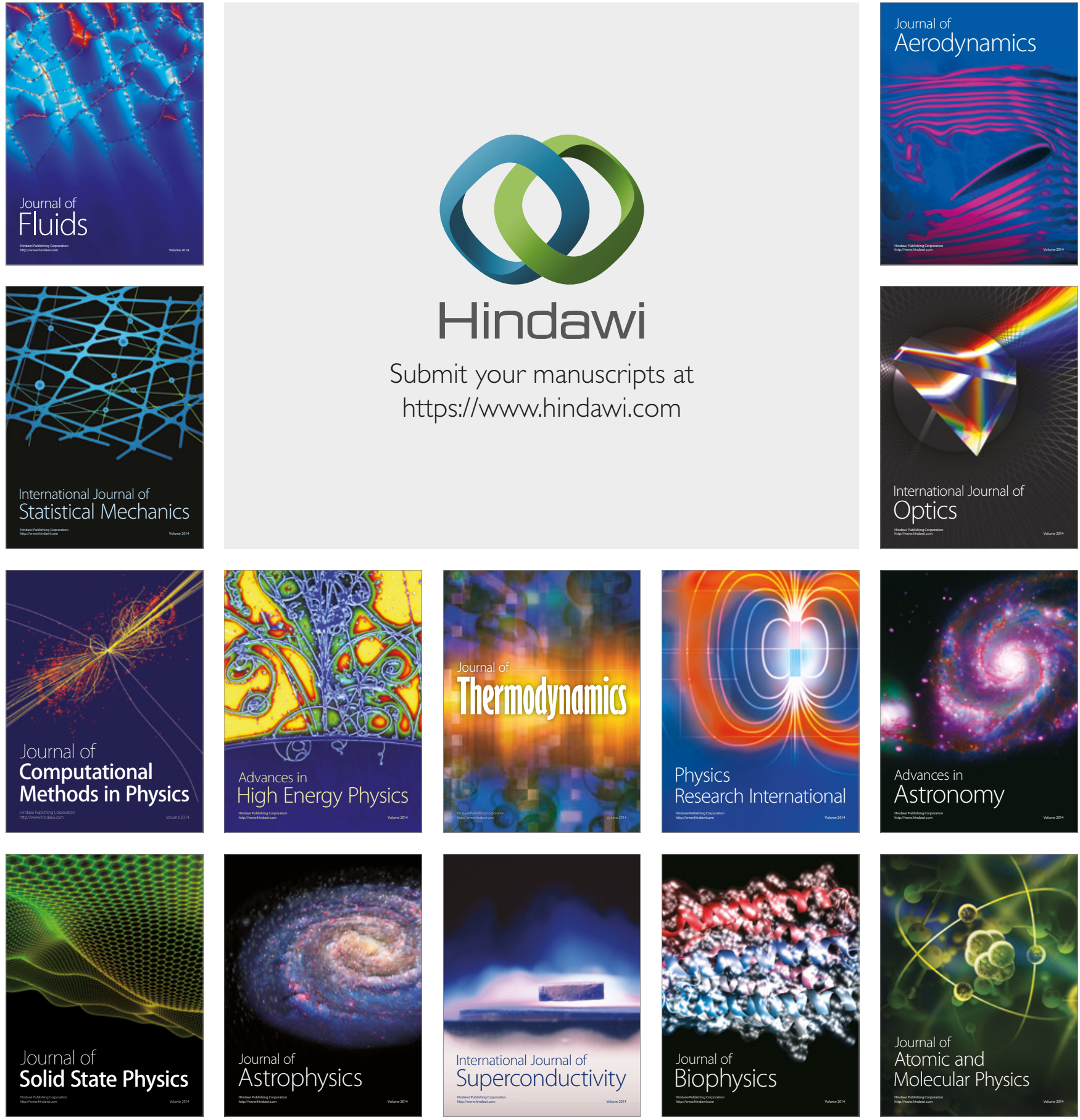